\title{
Sustainable consumption and scientific research
}

\author{
Subhas K. Sikdar
}

Published online: 9 November 2011

(c) Springer-Verlag (outside the USA) 2011

In the recent past I had the opportunity of participating in three conferences, each of which was sustainabilityfocused with an engineering orientation. As is typical these days, sustainability discussion always begins with unsustainability of consumption in contrast to declining natural resources. Engineering research community has responded with the idea of dematerialization, which is first and foremost an attempt to decouple economic growth, such as increase in gross domestic product (GDP), from adverse environmental impact. This has been shown in some cases to have already been achieved partially; however, the goal remains to be full decoupling. Secondarily, dematerialization is directed towards reducing use of limited natural resources to satisfy the growing functional need of consumption. Dematerialization, while providing a useful idea towards efficient resource use, does not guarantee less consumption per capita. Great innovations in the future can be expected to come from scientific and engineering research to meet the decoupling objective.

Directing research directly to reducing per capita consumption of material and energy, however, is another objective which could use the idea of dematerialization. The argument for sustainable consumption goes like this: the developed countries are unfairly using, on a comparative basis, far more material and energy consumption per capita than the developing countries. According to this line of thinking, the standard of living is not necessarily tied to larger per capita resource use. One illustrative example is the use of automobiles. Personal ownership of automobiles

S. K. Sikdar $(\bowtie)$

National Risk Management Research Lab/USEPA, 26 W. M.L. King Dr., Cincinnati, OH 45268, USA

e-mail: sikdar.subhas@epa.gov is not central to enjoying the function or service that automobiles deliver. Thus, if the ownership could be restricted in favor of rental, the same benefit can be obtained with fewer automobiles per capita, thereby reducing per capita resource use, pollution creation and environmental footprint. Some congested parts of the developed world, such as New York City and Washington, DC, already use this idea to a small extent. Greater good is and can be served by public transportation as well. Similarly, one could argue that per capita living space in square feet per person, which is comparatively large in developing nations, could also be reduced without reducing comfort and standard of living, thereby reducing environmental footprint and saving valuable resources for the future generation. If one continues to argue in this fashion, one arrives at the inevitable conclusion that human progress can be decoupled from personal consumption. The problem is that the acceptance of this decoupling can only be forced, as people will tend to spend when they earn. Thus, earnings need to be restricted. There is no science or engineering in this prospect. The only ways restriction of consumption or earnings can be implemented is either voluntary societal choice, which is unlikely, or force, which only a government can, in theory, exercise uniformly on all people. I asked one passionate adherent to sustainable consumption, who organized one of the conferences, if forced societal choice is different from socialism. He vehemently opposed this proposition, but still held that scientific and engineering research can provide solutions for a sustainable planet, which must of necessity, enjoy restriction on consumption. There will be myriads of innovative engineering solutions in the future that will bring that about, without the need to resort to force. Instruments of political economy, such as taxation and tariff, can effectively be used to curb demand. Unsustainability of our consumption is so dire, he argued, 
that we must reduce consumption to save the planet and its ecological services for the future generations.

The problem is of course exceedingly complex with every intervention leading to anticipated and unanticipated tradeoffs. Any social organization, spontaneously arrived at or forced into being, thus far experienced by man, has been troubled by inequality of income and wealth. Some of these organizations promoted technological innovations more efficiently than others. Scientific and engineering research undoubtedly can lead to efficient products and processes that use less non-renewable resources. Such efforts will take us to a more sustainable state. In the margin some restriction of consumption choices can provide some efficiency, but a large scale curbing covering entire nations will likely not be attainable by technical means. History tells us that any other means will severely tell upon innovations for improving living standards, as we know them. 